\title{
THEODORO PECKOLT: NATURALISTA E FARMACÊUTICO DO BRASIL IMPERIAL
}

\section{Nadja Paraense dos Santos, Angelo C. Pinto e Ricardo Bicca de Alencastro}

Instituto de Química - Universidade Federal do Rio de Janeiro - CT Bloco A - Sala 609 - Cidade Universitária- 21945-970 Rio de Janeiro - RJ

Recebido em 10/6/97; aceito em 26/2/98

\begin{abstract}
THEODORO PECKOLT: NATURALIST AND PHARMACIST OF THE BRAZILIAN EMPIRE. In this paper we briefly describe the scientific career of Theodor Peckolt, naturalist and pharmacist, and his seminal contribution to the development of phytochemistry in Brazil. His achievements are discussed in the light of the historical background of the Brazilian science and University at his time.
\end{abstract}

Keywords: phytochemistry; history; Peckolt.

\section{INTRODUÇÃO}

Pode-se dizer, com Franken ${ }^{1}$, que as primeiras manifestações científicas originadas no Brasil foram as observações sobre a flora e fauna descritas por Pero Vaz de Caminha em sua famosa carta ao Rei de Portugal. Menos conhecidas, mas igualmente importantes foram as primeiras observações astronômicas realizadas no Brasil, registradas pelo físico e cirurgião Mestre João, que acompanhava Cabral, em carta a D. Manuel I (1469-1521) 2 . Começa aí uma longa história, que se prolonga pelos séculos seguintes, em que nossa terra é vista ora com os olhos cobiçosos dos caçadores de fortunas, ora com os olhos exóticos dos sonhadores de paraísos perdidos. Em paralelo, descrições fantasiosas e científicas vão se acumulando, a partir de Hans Staden, com seu livro "Duas Viagens ao Brasil", de 1557, de André Thévet, com seu "As Curiosidades da França Antártica", de 1558, e, principalmente, de Jean de Léry, com sua "Viagem à Terra do Brasil", publicada em Paris, em 1578. Estas obras acenderam a curiosidade européia ao ponto de fazer com que uma das condições que impôs Catarina de Médicis, Rainha da França, para intervir na guerra da sucessão de D. Sebastião em favor de D.Antônio, foi que o Prior do Crato, um dos pretendentes, uma vez entronado, lhe cedesse os direitos da Coroa Portuguesa sobre o Brasil, o que foi prontamente aceito ${ }^{3,4}$.

Muito pouco ocorreu no Brasil Português dos Séculos XVI e XVII do ponto de vista do desenvolvimento de uma mentalidade científica. Destacamos as seguintes obras deste período: "História da Província de Santa Cruz (a que Vulgarmente Chamamos Brasil)", de Pero de Magalhães Gandavo, publicada em Lisboa em 1576, que era uma versão mais completa do "Tratado da Terra do Brasil" (escrito em 1570, porém só impresso em Lisboa em 1826) ${ }^{5}$, o "Tratado Descritivo do Brasil" de 1587, escrito por Gabriel Soares de Souza mas somente publicada em Lisboa no início do Século XIX, cuja autoria só foi definitivamente estabelecida por Varnhagen em $1839^{5}$, os "Diálogos das Grandezas do Brasil", de 1618 e autoria desconhecida (publicados integralmente pela primeira vez na Revista do Instituto Arqueológico Pernambucano e atribuídos, por Capistrano de Abreu e Rodolfo Garcia, a Ambrósio Fernandes Brandão), em que se dá idéia das condições sociais e econômicas do Nordeste do Brasil, e a "História do Brasil" de Frei Vicente do Salvador, escrita em 1627 (e publicada pela primeira vez em 1887, no Rio de Janeiro, por iniciativa de Capistrano de Abreu, pela Imprensa Nacional).

A estas descrições vêm se juntar as iniciativas dos invasores estrangeiros. Assim, da aventura francesa no Maranhão tivemos a "História da Missão dos Padres Capuchinhos na Ilha do Maranhão e Terras Circunvisinhas" de Claude
d'Abbeville, escrita e publicada em 1615, em Paris, e, de Yves d'Evreux, seu acompanhante, a "Seqüência da Historia dos Acontecimentos Memoraveis Acontecidos no Maranhão nos Anos 1613 et 1614", também de 1615. Da conquista holandesa, menos efêmera, além de publicações de observações de naturalistas e geógrafos, foi marcante a instalação em uma das torres da residência de Maurício de Nassau - que chegara ao Brasil sob a chancela da Companhia das Índias Ocidentais para consolidar a nova colônia holandesa e aumentar o comércio na ilha de Antônio Vaz, na região de Olinda, de um obsevatório astronômico, o primeiro do hemisfério austral.

São deste período os estudos dos naturalistas e médicos holandeses Marcgrave e Piso, autores da "Historia naturalis Brasiliae", uma obra importante sobre a flora e a fauna brasileiras $^{6}$. Após a derrota holandesa em 1654, já quase no fim do reinado de D.João IV (1604-1656), o pouco que havia sido feito em Pernambuco perdeu-se. As exigências econômicas e políticas da época, catalisadas pelo desenvolvimento da economia agrária e a descoberta das minas de ouro e diamantes, reorientaram-se no sentido do desenvolvimento dos estudos de engenharia e cartografia, necessários à demarcação territorial e à defesa militar do novo estado que ia se formando. Assim, alguns cursos de engenharia, muito precários, foram se estabelecendo. A Aula de Fortificação, criada no Rio de Janeiro, e a Escola de Artes e Fortificações Militares, criada na Bahia, são de $1699^{1}$.

No século XVIII - dos monarcas influenciados pelo Iluminismo e empenhados no incentivo aos estudos e reformas inovadoras - registra-se a primeira missão científica regularmente instituída e esta é portuguesa, presidida pelo brasileiro Alexandre Rodrigues Ferreira, natural da Bahia, um ex-aluno de Domingos Vandelli (1730-1816), primeiro catedrático de química e história natural em Coimbra. Rodrigues Ferreira foi encarregado de chefiar a exploração da fauna e flora brasileiras, esta expedição ficou conhecida como "Viagem Filosófica". Percorrendo o norte do Brasil de 1783 a 1792, retornando a Portugal com várias coleções que foram, em sua maioria, depositadas no Museu da Ajuda, em Lisboa. Quando o general Junot, a mando de Napoleão, invadiu Portugal em 1808, os museus portugueses foram saqueados e muitas destas coleções foram parar em Paris, nas mãos de Etienne Geoffroy Saint-Hilaire (1772-1844), um importante zoólogo, que, sem nunca ter vindo ao Brasil, descreveu inúmeras espécies de nossa fauna e flora ${ }^{7}$.

No Brasil, por outro lado, do período colonial até o segundo decênio do século XIX, quase nada se fez em química, embora possamos dizer que o período colonial caracterizou-se por atividades produtivas ligadas a uma química de produtos naturais, de origem orgânica ou mineral ${ }^{8,9}$. A indústria da canade-açúcar, por exemplo, utilizava um conjunto de processos e 
operações químicas e físicas de natureza empírica que exigiam conhecimentos técnicos precisos. Como, porém, a sociedade açucareira da época do ciclo da cana-de-açúcar não estava interessada no desenvolvimento da tecnologia e o uso da mão de obra escrava tornava isto possível, as técnicas permaneceram inalteradas por muito tempo ${ }^{10}$. Algumas plantas medicinais conhecidas dos índios tornaram-se importantes. Foi o caso da ipecacuanha ou poaia (Cephaelis ipecacuanha) que fornece a emetina, alcalóide usado no tratamento da amebíase, da iuapecanga ou salsaparrilha, usada como depurativo, da copaíba (Copaifera langsdorfii), da jurubeba, da bicuíba, do jaborandi (Pilocarpus jaborandi), que fornece a pilocarpina, um alcalóide usado no tratamento do glaucoma, plantas estas, que ainda hoje são muito utilizadas ${ }^{11}$. Algumas fibras vegetais eram aproveitadas, como as do caraguatá-piteira (Bromelia karatas) usadas em cordoaria e tapetes, as do tucum (Bactris setosa), uma palmeira cujas sementes dão um óleo comestível, as do caroá (Neoglaziovia variegata), usadas em barbantes, linhas de pesca e tecidos, e as da guaxima (Urena lobata), que foi utilizada na fabricação de cordas no tempo do Vice-Rei $2^{\circ}$ Marquês do Lavradio. Plantas aromáticas, como o pau-rosa (Aniba rosaeodora), cujo óleo essencial é rico em linalool, eram usadas em perfumes. Plantas exóticas foram aclimatadas, inclusive a cana-de-açúcar, o café e o côco. O urucu, fruto do urucuzeiro (Bixa orellana), uma planta nativa, era usado na fabricação de tintas e como condimento, em substituição ao açafrão. $\mathrm{O}$ urucu chegou a ser tão importante economicamente que uma carta-régia determinou, em 1693, a criação, no Maranhão, de uma "fábrica de urucu e outras drogas" ",10. Outras plantas importantes foram o cacaueiro (Theobroma cacao), descoberto no Pará, do qual os índios usavam a geléia preparada das amêndoas como alimento, a castanheira-do-pará (Bertholletia excelsa), a seringueira (Hevea brasiliensis), o guaraná (Paullinia cupania), o açaí (Euterpe oleracea) e o pequi (Caryocar brasiliense), dentre outras. Da anileira (Indigofera anil) era extraído o anil (indigo), a princípio no Pará, depois, na região de Cabo Frio, no Rio de Janeiro ${ }^{4}$.

A partir do século XIX, boa parte das explorações de caráter naturalístico no Brasil foi realizada por estrangeiros. A insuficiência dos recursos nacionais não foi a única explicação deste fato. Tiveram também grande peso a abertura dos portos às nações amigas, em 1808, e a influência, a partir de 1817, de D. Leopoldina, uma devotada naturalista ${ }^{12}$. Acompanhando a futura Imperatriz, vieram os naturalistas Carl Friedrich von Martius (médico e botânico) e Johann Baptist von Spix (zoólogo), cujas observações são, sem dúvida, as mais conhecidas. Estes naturalistas tomaram parte em uma viagem científica, custeada pelos governos austríaco e bávaro no período de 1817 a 1820 , e foram responsáveis por uma descrição muito extensiva da flora e da fauna brasileiras.

Após os naturalistas, vieram os geógrafos, geólogos e paleontólogos, como Varnhagen e Peter Lund. São também desta época as viagens de Auguste de Saint-Hilaire, um naturalista francês, e do barão Georg Heinrich von Langsdorff, ou Grigori Ivanovitch Langsdorff como era conhecido na Rússia. Langsdorff chegou pela primeira vez ao Brasil em dezembro de 1803, desembarcando na Província de Santa Catarina durante uma viagem de circunavegação do mundo, lá ficando até fevereiro de 1804. Langsdorff voltou mais tarde ao Brasil, na condição de Cônsul da Rússia no Rio de Janeiro, e aí escreveu o primeiro guia para os europeus que quisessem emigrar para o Brasil, publicado em alemão (1821). Langsdorff possuia uma fazenda em Petrópolis, a Fazenda Mandioca, e a tranformou no ponto de encontro dos viajantes estrangeiros que visitavam o Rio de Janeiro. Von Martius e Spix por lá passaram.

Foi por sugestão de von Martius que o jovem farmacêutico Theodoro Peckolt veio ao Brasil, em 1846, para estudar-lhe a flora. Seu trabalho iniciou o estudo químico sistemático da flora brasileira. A figura 1 localiza a atividade de Peckolt no século XIX:

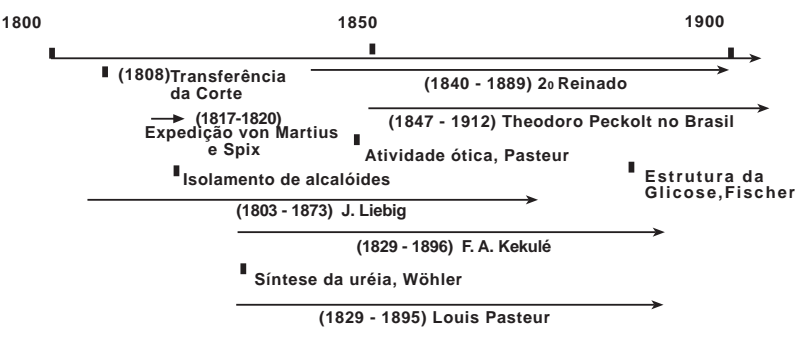

Figura 1.

\section{THEODORO PECKOLT}

Theodoro Peckolt nasceu em Pechern, na Silésia alemã, em 13 de julho de 1822. Sua paixão pela química e pelas plantas começou muito cedo. Peckolt revelou sua vocação, trabalhando como prático em farmácias. Mais tarde, prestou serviço militar como farmacêutico na fortaleza de Glogau ${ }^{13}$. Estudou farmácia, posteriormente, nas Universidades de Rostock e Göttingen e, em 1846, começou a trabalhar no Jardim Botânico de Hamburgo ${ }^{14}$. Foi contemporâneao de importantes cientistas como von Martius, Eichler, Wiegand, Goeppert, Hanbury, Oberdoerfer e Dietrich. Reconhecendo as aptidões de Peckolt, von Martius o induziu a visitar o Brasil na excursão científica de 1847 , a fim de estudar a flora tropical e remeter-lhe o material colecionado. Peckolt embarcou no navio "Independência" em 28 de setembro, chegou ao Brasil em novembro e aqui permaneceu os restantes 65 anos de sua vida.
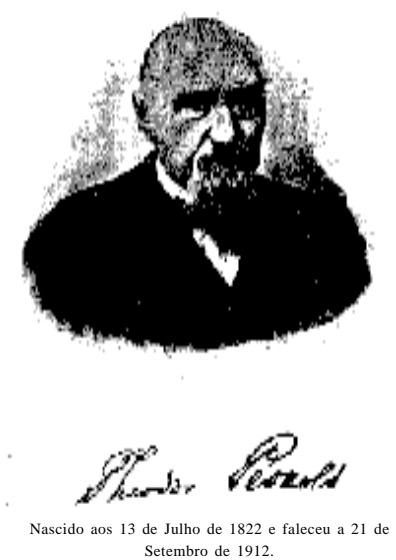

Figura 2. Retrato de Theodoro Peckolt.

Em janeiro de 1848, Peckolt empregou-se na farmácia de Mariolino Fragoso, e como havia aprendido nossa língua em uma pequena gramática da língua portuguesa que havia copiado e decorado na viagem de navio, as pessoas não conseguiam entender o que falava em português. Todas as conversas eram feitas por escrito, que Peckolt traduzia por dicionário. Foi desta forma que aviou suas primeiras receitas. Nos sete meses em que ficou nesta farmácia, Peckolt aprendeu a falar um português sofrível e conseguiu juntar o dinheiro necessário para comprar um animal de sela e preparar a viagem. Tudo apesar dos apelos de Fragoso, que lhe propôs fazer o exame de suficiência e dar-lhe sociedade na farmácia ${ }^{13}$.

Em setembro de 1848, Peckolt começou sua exploração do país: viajando a cavalo, percorreu as Províncias do Espírito Santo, Minas Gerais e Rio de Janeiro, estudando-lhes a flora. Existiam, então, poucos médicos no interior e os conhecimentos farmacêuticos do jovem naturalista colocavam-no na posição vantajosa de poder prestar reais serviços aos doentes que o 
consultavam. Como compensação destes serviços recebia, além dos honorários, objetos interessantes de história natural e contribuições valiosas para sua coleção botânica. No início de 1850 , passou algum tempo com os botocudos nacnanouc do rio Doce, antes de voltar para o Rio de Janeiro. Os recursos que poupou permitiram a Peckolt manter-se na Corte por algum tempo. Apresentou-se ao exame farmacêutico na Escola de Medicina do Rio de Janeiro em julho de 1851 e foi aprovado. Em novembro do mesmo ano, estabeleceu-se em Cantagalo (Rio de Janeiro), a convite de médicos e fazendeiros alemães e suiços. Ali comprou uma farmácia e casou-se, em 12 de junho de 1854 , com D. Henriqueta, filha do vigário protestante da colônia alemã de Friburgo, cidade da qual foi um dos fundadores. Peckolt preferia Cantagalo a Friburgo porque a cidade estava mais próxima das matas do vale do rio Doce, o que tornava as expedições mais baratas. Viajava em companhia de dois índios como guias e para maior segurança, acompanhava as tropas do exército que por ali passavam ${ }^{14}$. Em suas viagens percorreu grande parte do vale do Paraíba e as margens dos rios Pomba e Doce. Atravessou grande parte do estado de Minas, fazendo de Diamantina seu centro de operações. Sua contribuição para a Flora Brasiliensis, de von Martius, foi vultuosíssima, distinguindo-o este cientista com a máxima confiança. Sua colaboração não se limitou ao fornecimento de materiais: von Martius e seus colaboradores enviavam-lhe as provas tipográficas de textos e desenhos para que fossem comentados e corrigidos. Nestas excursões colheu muito material até então desconhecido, que hoje enriquece o Museu Nacional no Rio de Janeiro, vários museus da Alemanha, e museus de Estocolmo e Upsala.

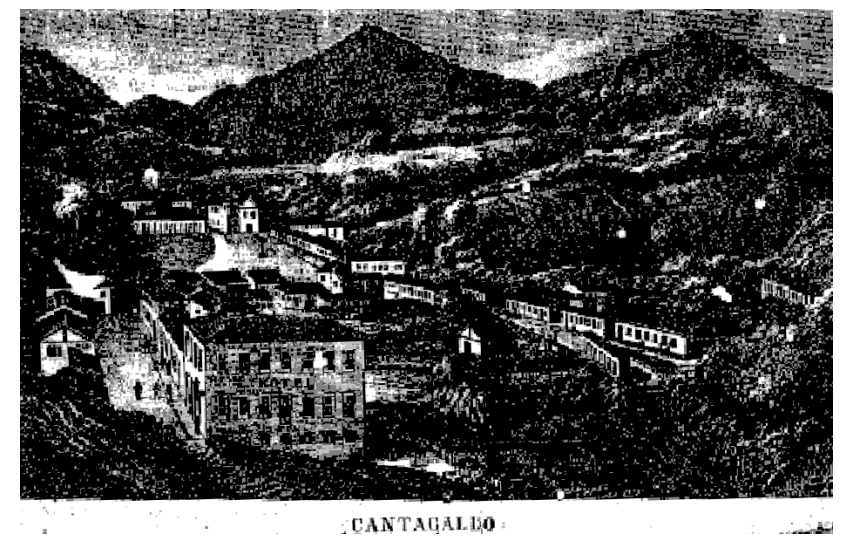

Figura 3. Capa do bloco da Farmácia Peckolt, com a vista da cidade de Cantagalo.

Peckolt permaneceu em Cantagalo até 1868, e ali realizou cerca de quinhentas análises quantitativas de extratos de plantas da flora brasileira, grande parte das quais foram publicadas em revistas internacionais. Algumas destas análises ainda hoje são únicas, como a do guaraná da Amazônia. Ele estudou plantas brasileiras de diversas famílias, observando as condições nas quais vivem e se multiplicam, recolheu dos nativos informações sobre nomes triviais, usos e propriedades farmacêuticas. O herbário fornecialhe os meios para a comparação morfológica das numerosas espécies e, no laboratório, Peckolt aprofundava o trabalho, obtendo informações detalhadas sobre a composição química das plantas medicinais, seus alcalóides e outras substâncias de extração. "Não conhecemos", diz Hermann von Hering, "outro exemplo de naturalista, versado igualmente, em estudos botânicos e químicos, que tão profundamente tivesse estudado e esclarecido por investigações próprias, o estudo econômico, farmaceutico e químico de qualquer flora tropical". Peckolt ocupou-se também de questões zoológicas, dentre as quais destacamos o estudo das Trigoniidas, as abelhas sociais do Brasil.
No período de 1852 a 1867, ainda residente em Cantagalo, recebeu muitas honrarias acadêmicas, foi nomeado Membro Correspondente da Real Sociedade Botânica de Regensburgo, recebeu igual distinção da Real Sociedade Farmacêutica da Alemanha. Foi feito Doutor Honoris Causa da Academia Cesária Leopoldino-Carolino-Germânica, instituição alemã que gozava então de grande prestígio. Em 1864, foi nomeado Oficial da Ordem da Rosa, por sua participação na Exposição Nacional do Rio de Janeiro (1861), na qual obteve medalha de ouro $^{13}$. Os produtos naturais que então apresentou incluiam frutos, sementes, cascas, raízes, óleos, resinas, gomas, sucos e extratos, dentre outros, e estavam prontos para uso farmacêutico $^{16}$. Esta coleção foi integralmente remetida para a Exposição Universal de Londres (1862), "sendo recomendada não só pelo seu interesse científico, como ainda pelo alcance que alguns dos preparados que aí se encontram, podem e devem ter em relação aos interesses das indústrias e sobretudo da farmacologia. Aí se encontram diferentes princípios imediatos, ou outros inteiramente novos, pela primeira vez isolados de substâncias indígenas"16. Peckolt participou também em 1867 da Exposição Geral do Rio de Janeiro e da Exposição Universal de Paris, onde exibiu alguns produtos da Sapucainha que lhe valeram outro prêmio.

Em abril de 1868 mudou-se definitivamente para a Corte, onde fundou a Farmácia Peckolt, na Rua da Quitanda, 157, (posteriormente, 197) ${ }^{17}$. Nela mandou construir um laboratório em que continuou a analisar nossas plantas. Pouco depois recebeu, das mãos do Duque de Saxe, um dos genros de D.Pedro II, o título de Farmacêutico da Casa Imperial. Foi membro correspondente de todas as sociedades farmacêuticas da Áustria e da Rússia e foi agraciado pelo Rei da Suécia com o título de Comendador da Estrela do Norte. Foi membro honorário da Sociedade de Geologia de Buenos Aires e sócio honorário das sociedades farmacêuticas da Inglaterra.

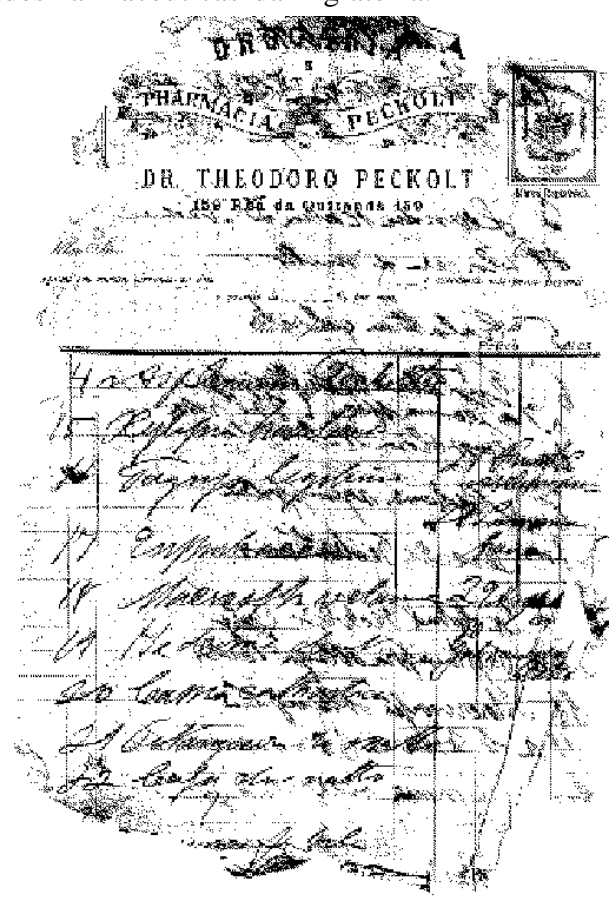

Figura 4. Receituário da Drogaria e Farmácia Peckolt do Rio de Janeiro.

Em 1874, Peckolt foi contratado para reorganizar a seção de química analítica do Museu Nacional, cargo no qual permaneceu alguns anos. Ali, independente de suas ocupações normais, publicou numerosos trabalhos sobre Zoologia, Botânica, Fitoquímica e Entomologia nas principais revistas da Europa, da América do Norte e do Brasil. 
Peckolt analisou mais de 6.000 plantas brasileiras e publicou acima de 400 trabalhos científicos, dentre os quais algumas obras notáveis sobre plantas brasileiras. Ao tornar-se membro efetivo da Academia Imperial de Medicina apresentou uma Memória intitulada "Do Prumus Brasiliensis" que foi publicada na Gazeta Médica do Rio de Janeiro (1864), juntamente com um comentário assinado por João Vicente Torres Homem ${ }^{18}$.

Em 1863, ainda em Cantagalo, Peckolt publicou na Gazeta Médica do Rio de Janeiro um interessante artigo sobre o leite da Gameleira (Ficus cloloaria), usado pelo povo local, como um vermífugo de excelentes efeitos. Ele isolou do látex da casca uma substância, a que denominou doliarina, cujas propriedades descreveu.

Em pesquisa na Biblioteca Nacional, encontramos uma propaganda da Farmácia Peckolt, onde ele relata a eficácia dos pós de doliarina e ferro contra a opilação (Hipohemia intertropical), que era presente principalmente entre os escravos.

Theodoro Peckolt fez, entre 1861 e 1869, seus estudos mais relevantes sobre a Sapucainha ou chaulmoogra brasileira (Carpotroche brasiliensis Endlicher). Em 1868, nas suas "Análises da Matéria Médica Brasileira", Peckolt descreve melhor os frutos da Sapucainha, e recomenda seu óleo como sucedâneo do óleo de Chaulmoogra da Índia .

Ele descreveu, em 1861, os frutos e sementes desta Flacurtiácia ${ }^{19}$. Das sementes extraiu um óleo amarelado com odor de maçã, do qual isolou uma fração a que deu o nome de ácido carpotróchico, que é, provavelmente, uma mistura dos ácidos chaulmúgrico, hidnocárpico e górlico (Figura 5). Mais tarde, Peckolt publicou os resultados da análise da polpa do fruto e anunciou o isolamento, das sementes, de uma substância cristalina, a que chamou carpotrochina, mas que nunca mais foi mencionada na literatura. Do óleo, ele isolou um ácido graxo cristalino a que deu o nome de ácido estéreocarpotróchico, mas que é, possivelmente, o ácido hidnocárpico. A análise do óleo da Sapucainha feita por Peckolt em 1866 foi a primeira, no mundo, a ser publicada sobre óleos de Chaulmoogra. Somente treze anos depois, John Moss isolou os ácidos componentes do óleo de chaulmoogra da Índia. A análise mais completa do óleo da Sapucainha, porém, deve-se a Cole e Cardoso $(1937)^{20}$.

ácido chaulmúgrico - $24,2 \%$

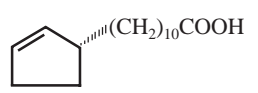

ácido hidnocárpico - 45\%

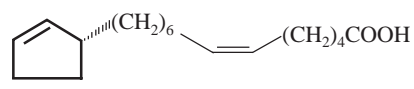

ácido górlico - 6,6\%

Figura 5.

Em 1870, já na sua farmácia, Peckolt estudou o plumerídio "agoniadina". Seu trabaho foi publicado no Archiv der Pharmazie. 82 anos depois, o assunto foi reestudado por Schmid, Bickel e Meijer $^{8,9}$. A estrutura química da "agoniadina", entretanto, só teve sua estrutura estabelecida em 1958, por Halpern e Schmid.

Peckolt publicou nas revistas mais importantes da época, tais como Pharmazeutische Rundschau (New York), Archiv der Pharmazie (Berlin), Zeitschrift des Oesterreich. Apothkerv (Wien), Berichte der Deutschen Pharmazeutischen Gesellschaft (Berlin), Pharmazeutischen Centralhalli, Gazeta Médica Rio de Janeiro, Pharmaceutical Review (Milwaukee), Die Natur e Die

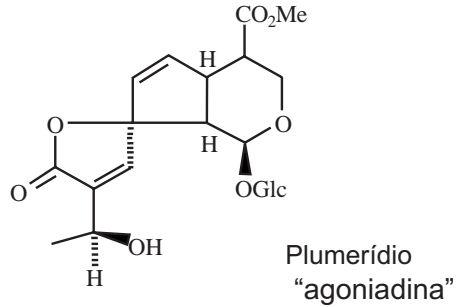

Figura 6.

Kultur. Destacam-se dentre seus livros: “Análises da Matéria Médica Brasileira", 108 páginas, (1868), "História das Plantas Alimentares e de Gozo do Brasil", em 5 fascículos (1871 a 1888) e "História das Plantas Medicinais e Úteis do Brasil", em 8 fascículos (1888 a 1914 -póstumo), esta última escrita em colaboração com seu filho, também farmacêutico, Gustavo Peckolt. Este trabalho descreve a classificação botânica e as técnicas de cultura, partes próprias para uso, composição química, usos em diversas moléstias, doses e usos industriais de plantas brasileiras. Seus livros "História das plantas alimentares e de gozo do Brasil" e "História das plantas medicinais e úteis do Brasil" são citados ainda hoje, uma vez que são as únicas publicações sistematizadas do gênero.

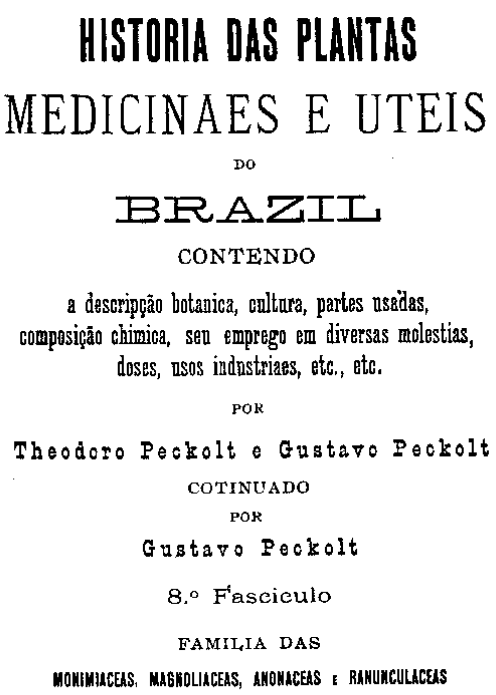

TO DE JANEIRO

Pap. MODELO - Rua da Quitanda, 165

1914

Figura 7. Capa da "História das Plantas Medicinais e úteis do Brasil, $80^{\circ}$ fascículo, 1914.

Em 13 de julho de 1892, quando Peckolt completou 80 anos, seu prestígio internacional era tal, que recebeu como presente um álbum com 125 fotografias de professores de Universidades alemãs, francesas, inglesas, austríacas e norte-americanas , todas com dedicatórias e assinaturas autênticas ${ }^{13}$.

É singular, que os resultados obtidos por este incansável cientista tivessem sido tão pouco conhecidos e apreciados no país que ele adotou. Com seu falecimento em 1912, desapareceu o último representante dos botânicos como Glaziou, Ule, Dusen, Mueller e Barbosa Rodrigues, que por numerosas publicações e criação de coleções promoveram o conhecimento da flora do Brasil. 


\section{REFERÊNCIAS}

1. Franken, T. G.; in Formação da Comunidade Científica no Brasil; Schwartzman, S., ed.; FINEP, Rio de Janeiro, 1979.

2. Azevedo, F. de; A Cultura Brasileira; $5^{\text {a }}$ ed, Ed. Melhoramentos, Editora da USP, São Paulo, 1971.

3. Mariéjol, J.-H.; Catherine de Medicis, $2^{\mathrm{a}}$ ed., Hachette, Pari,s 1920.

4. Vianna, H.; História do Brasil, $15^{\mathrm{a}}$ ed. (revista), Melhoramentos, São Paulo, 1994.

5. Vogt, C. e Lemos, J. A. G.; Cronistas e Viajantes, Abril Educação, São Paulo, 1982.

6. Schwartzman, S.; Formação da Comunidade Científica no Brasil, FINEP, Rio de Janeiro, 1979.

7. Pinto, A. C.; Quím. Nova 1995, 18, 608.

8. Mathias, S.; Coleção da Revista de História, 1975, vol. LXIII, Dep. de História da Fac. Filos. Letras e Ciências Humanas, USP, São Paulo.

9. Mathias, S.; "A História da Química" in História das Ciências no Brasil, Ferri, M. G; Motoyama, S. (org), EPU: Ed. da USP, São Paulo, 1979.

10. Antonil, A. J.; Cultura e Opulência do Brasil por suas Drogas e Minas, Oficina Real Deslandesiana, Lisboa, 1711 (Cópia xerográfica, arquivo pessoal Min. Israel Vargas).
11. Pio Corrêa, N.; Dicionário das Plantas Úteis do Brasil, Min. Agricultura, Instituto Brasileiro de Desenvolvimento Florestal, 6 volumes, Brasília, 1984.

12. Filgueiras, C. A. L.; Quím. Nova 1990, 13, 222.

13. Peckolt, O.; Entrevista Particular (em 6 de novembro de 1995)

14. Mendonça, H. B. M.; Necrológio, Revista Agrícola do Rio de Janeiro, Rio de Janeiro, 1912.

15. Teschauer, C.; "Os Naturalistas Viajantes dos Séculos XVIII e XIX no Brasil"; Congresso Internacional de História Americana, vol 5, 367-381,1922.

16. Cunha, A. L. F. da; Relatório Geral da Exposição Nacional de 1861, Tipografia do Diário do Rio de Janeiro, Rio de Janeiro, 1862.

17. Gerson, B.; História das Ruas do Rio, Coleção Vieira Fazenda, vol IX. Maciel Pinheiro, ed.; 4⿳. ed., Livraria Brasiliana, Ed., Rio de Janeiro, 1965.

18. Gazeta Médica do Rio de Janeiro, (1862-1864), Tomos I, II, III; Edgard de Cerqueira Falcão, ed, São Paulo, 1976.

19. Araújo, H. C. S. de; História da Lepra no Brasil; I, Imprensa Nacional, Rio de Janeiro, 1946.

20. Possolo, H.; As flacourtiáceas antilepróticas, Secretaria de Agricultura, Indústria e Comércio de São Paulo, São Paulo, 1945. 